\title{
Çok Seviyeli H-Köprü Temelli Gerilim Kaynaklı Eviricili STATCOM'un BMD'li Kontrolü ve Karşılaştırmalı Benzetimi
}

\author{
$\underline{\text { Kenan YANMAZ }}^{1}$, Onur Özdal MENGİ $\dot{I}^{\text {İsmail Hakkı ALTAŞ }}{ }^{3}$
}

${ }^{1}$ Giresun Üniversitesi, Teknik Bilimler MYO, Elektronik ve Otomasyon Bölümü, Giresun, TÜRKIYYE
${ }^{2}$ Giresun Üniversitesi, Mühendislik Fak, Enerji Sistemleri Mühendisliği Bölümü, Giresun, TÜRKİYE
${ }^{3}$ Karadeniz Teknik Üniversitesi, Mühendislik Fak, Elektrik Elektronik Mühendisliği, Trabzon, TÜRKIYE

Sorumlu Yazar: kenan.yanmaz@giresun.edu.tr

Geliş Tarihi: 15.11 .2016

Kabul Tarihi: 05.12.2016

\begin{abstract}
Özet
Geleneksel olarak kullanılan statik var kompanzatörler ve sabit mekanik anahtarlamalı kondansatör grupları iletim ve dağıtım sistemlerinde güç kalitesini arttırmak için kullanılmaktadır. Son yıllarda, bazı güç kalitesi iyileştirici cihazlar enerji sistemlerinde reaktif güç kompanzasyonu için geliştirilmiştir. Esnek Alternatif Akım İletim Sistemleri (FACTS) cihazları güç kalitesi iyileştirici cihazlardır. Bu FACTS cihazlarından birisi de Statik Senkron Kompanzatör (STATCOM) cihazıdır. STATCOM evirici temelli güç kalitesi iyileştirici cihazıdır ve enerji sistemlerinde güç kalitesini iyileştirmek için kullanılır. STATCOM yapısında kullanılan gerilim kontrollü evirici, klasik iki seviyeli yapılabildiği gibi çok seviyeli de yapılabilmektedir. STATCOM cihazının kontrolü genellikle sabit parametreli PI kontrolörlerle gerçekleştirilmektedir. Bununla birlikte istenilen kontrol performansı doğrusal olmayan yapılardan dolayı elde edilememektedir. Bu çalışmada STATCOM'un kontrolü için senkron referans yapı teorisine dayalı dolaylı akım denetim yöntemi kullanılmıştır. Bu denetim yöntemindeki d ve q eksen akımlarının kontrolünde kuvvetli bir yapıya sahip Bulanık Mantık Denetleyici (BMD) kullanılmaktadır. Benzetim çalışmaları Matlab/Simulink yazılım ortamında yapılmıştır. Klasik iki seviyeli evirici ile beş seviyeli evirici yapıları kullanılarak yapılan benzetim çalışmaları kıyaslanmaktadır.
\end{abstract}

Anahtar kelimeler: STATCOM, Bulanık Mantık Denetleyici, H-köprü, beş seviyeli evirici.

\section{Multi-Level H-Bridge Voltage Source Inverter Based STATCOM Control with FLC and Comparative Simulation}

\begin{abstract}
Traditionally used static compensators and fixed mechanical switched capacitor groups are used to improve the quality of power in transmission and distribution systems. In recent years, some power quality remediation devices have been developed for reactive power compensation in energy systems. Flexible Alternating Current Transmission Systems (FACTS) are power quality improvement devices. One of these FACTS devices is the Static Synchronous Compensator (STATCOM) device. STATCOM is an inverter based power quality healing device and is used to improve the quality of power in energy systems. The voltage-controlled inverter used in STATCOM construction can be made in classical two levels as well as multilevel. The control of the STATCOM device is usually performed by PI controllers with fixed parameters. However, the desired control performance cannot be achieved due to nonlinear structures. In this study, indirect current control method based on synchronous reference frame theory is used to control STATCOM. The Fuzzy Logic Controller (FLC), which has a strong structure for controlling the $\mathrm{d}$ and $\mathrm{q}$ axis currents in this control method, is used. Simulation studies were performed in Matlab / Simulink software environment. The results are shown by comparing the two-level inverter with the five-level inverter.
\end{abstract}

Key words: STATCOM, Fuzzy Logic Controller, H-bridge, five level inverter. 


\section{Giriş}

Reaktif güç kompanzasyonu tüm enerji sistemlerinde bir ihtiyaçtır. Reaktif güç, farklı güç kalitesi problemlerine sebep olduğu gibi kayıpların artmasına da neden olur. Yıllardır kullanılan statik var kompanzatörler ve sabit mekanik anahtarlamalı kondansatör grupları çok geniş bir kullanıma sahiptirler. Bu tip kompanzasyonlar boyutlarının büyük olması, kayıpların fazla olması ve cevap süresinin yavaş olması gibi bazı dezavantajlara sahiptir. Günümüzde STATCOM gibi evirici tabanlı güç kalitesi iyileştirici cihazlar, hızlı cevap süresine, küçük boyutlara ve düşük kayıplara sahip olmalarından dolayı dağıtım sistemlerinde güç kalitesi problemlerini iyileştirmek için önerilmektedir. STATCOM genel olarak alternatif akım sistemlerinde güç kalitesi iyileştirici bir FACTS cihazıdır. STATCOM paralel bağlı evirici tabanlı bir cihazdır. Bu cihaz, enerji sistemlerinde güç faktörü iyileştirme, yük dengeleme, gerilim regülasyonu ve harmonik eliminasyonu gibi görevleri yerine getirmek için kullanılmaktadır (Çetin ve Ermiş, 2009).

STATCOM'un kontrolünde pek çok yöntem kullanılmaktadır (Kazmierkowski ve Malesani, 1998). Bu yapıda temel olarak bir adet gerilim kontrollü evirici bulunmaktadır. Fakat bu evirici yapısı çok seviyeli yapılabildiği gibi farklı güç elektroniği bağlantı şekilleri ile değişik türlerde de yapılabilmektedir. Burada STATCOM'un kontrolü için senkron referans yapı teorisine dayalı dolaylı akım denetim yöntemi kullanılmıştır. Bu kontrolde, d ve q eksen akımları için istenilen değer genellikle doğrusal kontrol yöntemi ile dizayn edilen PI kontrolörden elde etmektedir. PI kontrolörlerin tasarımında kontrol edilen sistemin doğrusal matematiksel modeli gereklidir. $\mathrm{Bu}$ kontrolörlerin parametreleri işlemin kısmi bir bölgesi için en iyi performansı elde edebilmek için tasarlanır. Fakat değişken parametreler, yük bozucular ve sistemin doğrusal olmayan dinamikleri altında memnun edici bir performans elde etmek zordur. Doğrusal kontrol yöntemlerinin dezavantajlarıyla başa çıkmak için bazı araştırmacılar doğrusal olmayan kontrol yöntemleri önermişlerdir. Bazı kontrol yöntemlerinin açık matematiksel modele ve kontrol sisteminin parametrelerine ihtiyacı vardır. Bunun yanında bu yöntemlerle kontrolör tasarımı çok karmaşık bir yapıya sahip olmaktadır ve doğrusal kontrolörlere göre anlaşılması daha zordur. Yakın zamanda bulanık mantık denetleyici ve yapay sinir ağları gibi akıllı kontrolörler, STATCOM'un kontrolünde kullanılmak üzere, doğrusal ve doğrusal olmayan kontrol tekniklerine 
alternatif olmaktadır. Kontrol edilmek istenen sistemin matematiksel modeli bazı kontrolörler için gereklidir. Üstelik onlar sistemin çalışma şartlarının geniş bir aralığında klasik doğrusal kontrolörlerden üstün olarak daha etkin bir kontrol sağlar.

$\mathrm{Bu}$ çalışmada, enerji iletim ve dağıtım sistemleri için kullanılacak olan STATCOM yapısında bulunan gerilim kontrollü evirici yapısı iki seviyeli ve beş seviyeli H-köprü temelli olarak gerçekleştirilmiştir. STATCOM'un d ve q eksen akımlarının kontrolünde güçlü bir kontrolör olan Bulanık Mantık Denetleyici önerilmektedir. Güç sisteminin, STATCOM'un ve kontrolörün modeli Matlab/Simulink ortamında geliştirilmiştir. İki adet BMD d ve q eksen akımlarını ayrı ayrı kontrol etmek üzere kullanılmaktadır. BMD'li kontrolörde d ve q eksen akımlarının hataları ile bu hatalar arasındaki fark giriş olarak kullanılmaktadır. Sürekli durum hatası BMD kontrolörün çıkışında harici integratör kullanılarak yok edilmektedir.

\section{Materyal ve Metodlar}

\section{STATCOM}

Alternatif akım iletim sistemleri, güç akışındaki denetim sistemlerinin yeterli olmamasından dolayı esnek olmayan bir yapıdadırlar. Son birkaç on yılda güç elektroniği elemanlarının geliştirilmesiyle güç sistemlerinde esnek alternatif akım iletim sistemleri kavramı sayesinde iletim sistemleri esnek yapıya dönüştürülmüştür. Güç elektroniği elemanları ve denetleyicilerle donatılmış alternatif akım iletim hatlarında, denetlenebilir olma özelliğini geliştirmek için ve güç aktarım kapasitelerini arttırmak için kullanılan cihazlar Esnek Alternatif Akım İletim Sistemleri olarak tanımlanabilir. Senkron kompanzatör, bobin ya da kondansatör grupları yerine güç elektroniği teknolojisinin kullanıldığı çeşitli reaktif güç kompanzatörleri geliştirilmiştir. Tristör denetimli reaktörler ve tristör anahtarlamalı kondansatörler kullanılarak oluşturulan statik VAR kompanzatörleri (SVC) geliştirilmiştir. Bu cihazlarla donatılmış sistemdeki reaktif güç alış verişi, sistem gerilimindeki değişiklikle değişim göstermektedir. Bu istenmeyen durum karşısında bu metotların yerine günümüzde STATCOM denilen statik kompanzatörler kullanılmaktadır. STATCOM, AC sistem geriliminden bağımsız olarak denetimi yapılabilen paralel bağlı bir statik senkron kompanzatördür. STATCOM' un hılı cevap zamanına sahip olması, daha az yer gereksiniminin olması, 
yüksek işletme esnekliğine ve farklı çalışma şartları altında çok iyi bir dinamik karakteristiğe sahip olması gibi önemli özellikleri vardır.

Statik Senkron Kompanzatör, şebeke frekansında bağlı olduğu sisteme sürekli olarak hem endüktif hem de kapasitif reaktif güç veren ya da sistemden reaktif güç çeken bir FACTS cihazıdır. STATCOM, şebeke frekansında sinüzoidal gerilim üreten ve faz açısı ve genliği denetlenebilen paralel bağlı bir senkron gerilim kaynağı olarak tanımlanabilir. STATCOM' un, bağlı olduğu sistemin empedansını önemli ölçüde değiştirmemesi SVC' lerden ayıran en önemli özelliğidir. Şekil 1'de görüldüğü gibi STATCOM, güç yarıiletken anahtarlama elemanları ile oluşturulmuş bir üç fazlı gerilim kaynaklı dönüştürücüden, anahtarlamalar için bir denetleyiciden, bu dönüştürücü yapısında bulunan anahtarlama elemanlarının neden olduğu değişen DC gerilimi sabit tutmak için enerji depolama elemanı olarak kullanılan DC kondansatörden oluşmaktadır. STATCOM dönüştürücü çıkış gerilimi ile AC sistem gerilimi arasındaki bağlantıyı sağlamak için de bir bağlantı transformatörü (ya da endüktansı) kullanılmaktadır.
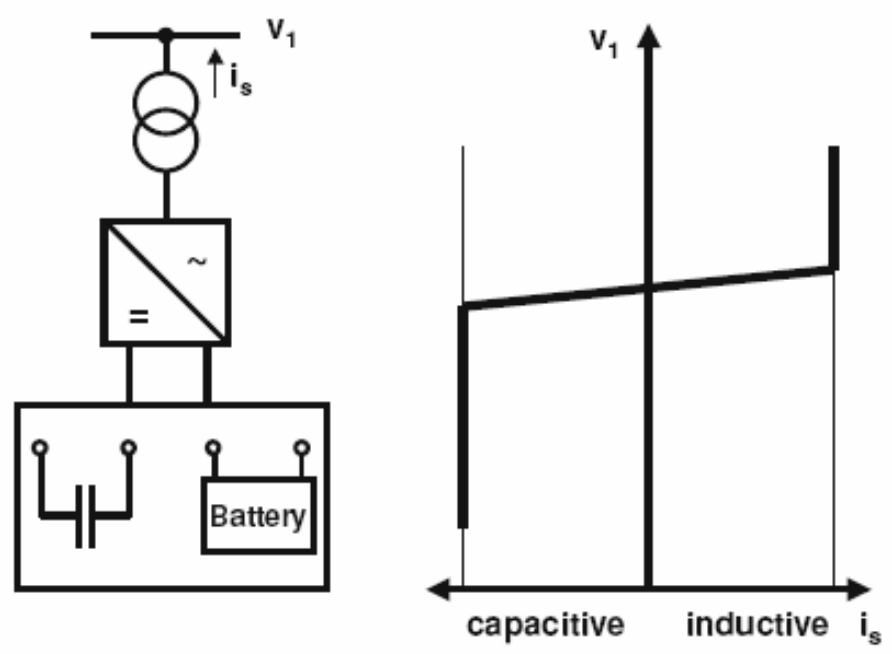

Şekil 1. STATCOM yapısı ve gerilim/akım karakteristiği.

STATCOM, iletim sistemlerinde sistemin kararlılığını geliştirmek ve gerilim düzenlemesini sağlamak için kullanılır. Dağıtım sistemlerinde ise gerilim düzenlemesinin yanında güç faktörünü düzeltme, yük dengeleme ve yükün harmonik kompanzasyonu için kullanılır. 


\section{STATCOM'un Matematiksel Modeli}

Şekil 2'de görülen STATCOM yapısında: C, DC tarafın kapasitesini; R, direnci; L, bobini; Usa, Usb, Usc, üç faz şebeke gerilimini temsil etmektedir. IGBT anahtarlama elemanları ideal ve üç faz şebeke gerilimi dengeli olarak kabul edilmiştir. Yüksek harmonikler de göz ardı edilmiştir.

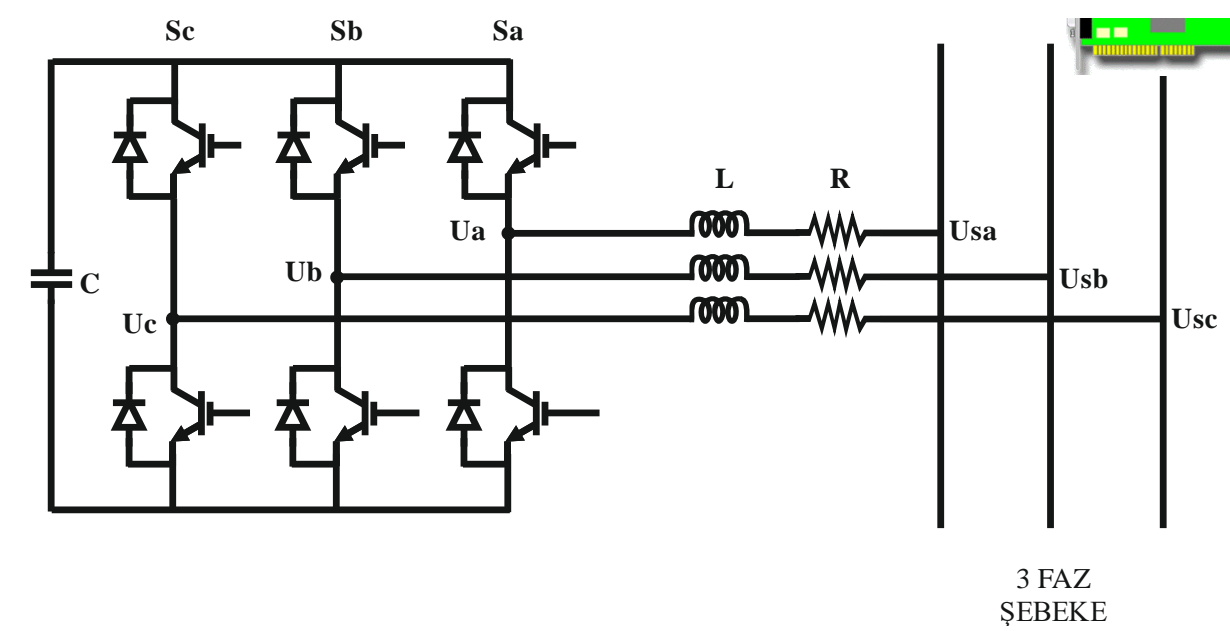

Şekil 2. Basit yapı olarak STATCOM.

ABC koordinat eksen şartları altında STATCOM matematiksel modeli denklem

(1)'de görülmektedir.

$$
\left\{\begin{array}{l}
\mathrm{L} \frac{\mathrm{di}_{\mathrm{a}}}{\mathrm{dt}}=\mathrm{U}_{\mathrm{a}}-\mathrm{Ri}_{\mathrm{a}}-\mathrm{U}_{\mathrm{sa}} \\
\mathrm{L} \frac{\mathrm{di}_{\mathrm{b}}}{\mathrm{dt}}=\mathrm{U}_{\mathrm{b}}-\mathrm{Ri}_{\mathrm{b}}-\mathrm{U}_{\mathrm{sb}} \\
\mathrm{L} \frac{\mathrm{di}_{\mathrm{c}}}{\mathrm{dt}}=\mathrm{U}_{\mathrm{c}}-\mathrm{Ri}_{\mathrm{c}}-\mathrm{U}_{\mathrm{sc}} \\
\mathrm{C} \frac{\mathrm{dU_{ \textrm {dc } }}}{\mathrm{dt}}=\mathrm{s}_{\mathrm{a}} \mathrm{i}_{\mathrm{a}}+\mathrm{s}_{\mathrm{b}} \mathrm{i}_{\mathrm{b}}+\mathrm{s}_{\mathrm{c}} \mathrm{i}_{\mathrm{c}}
\end{array}\right.
$$

sa, sb, sc anahtarlama fonksiyonlarıdır ve üstteki köprü kolu iletken olduğunda 1, alttaki iletken olduğunda 0 değerini alır.

$\mathrm{ABC}$ koordinat ekseninde bulunan denklem kontrol sisteminin tasarımı açısından, matematiksel modelin AC tarafindaki değişkenler zamana bağlı olduğundan dolayı, çok zor bir denklemdir. Bu sebeple ABC koordinat ekseni PARK dönüşümü yardımıyla iki faz koordinat eksenine dönüştürülür. $\mathrm{ABC}$ koordinat ekseninin matrisi iki faz eş 
zamanlı olarak dönen koordinat eksenine denklem (2)'deki PARK dönüşüm matrisi yardımıyla dönüştürülür.

$$
\mathrm{T}=\sqrt{\frac{2}{3}}\left[\begin{array}{ccc}
\cos \theta & \cos (\theta-2 \pi / 3) & \cos (\theta+2 \pi / 3) \\
-\sin \theta & -\sin (\theta-2 \pi / 3) & -\sin (\theta+2 \pi / 3) \\
\frac{1}{\sqrt{2}} & \frac{1}{\sqrt{2}} & \frac{1}{\sqrt{2}}
\end{array}\right]
$$

idq0= $\mathrm{T}^{*}$ iabc olarak dönüşüm yapılır. Bu iki denklem kullanılarak (3) numaralı denklem elde edilir.

$$
\left\{\begin{array}{l}
\mathrm{L} \frac{\mathrm{di}_{\mathrm{d}}}{\mathrm{dt}}=\mathrm{s}_{\mathrm{d}} \mathrm{U}_{\mathrm{dc}}-\mathrm{Ri}_{\mathrm{d}}-\mathrm{U}_{\mathrm{sd}}+\mathrm{Lwi}_{\mathrm{q}} \\
\mathrm{L} \frac{\mathrm{di} \mathrm{q}_{\mathrm{q}}}{\mathrm{dt}}=\mathrm{s}_{\mathrm{q}} \mathrm{U}_{\mathrm{dc}}-\mathrm{Ri}_{\mathrm{q}}-\mathrm{U}_{\mathrm{sq}}-\mathrm{Lwi}_{\mathrm{d}} \\
\mathrm{C} \frac{\mathrm{dU_{ \textrm {dc } }}}{\mathrm{dt}}=\frac{3}{2}\left(\mathrm{~s}_{\mathrm{d}} \mathrm{i}_{\mathrm{d}}+\mathrm{s}_{\mathrm{q}} \mathrm{i}_{\mathrm{q}}\right)
\end{array}\right.
$$

id ile iq iki faz dönen koordinat ekseninin direk akım bileşenini, sd ile sq ise anahtarlama fonksiyonlarını temsil etmektedir. Böylece sistem eşitliği büyük oranda basitleştirilmiş olur. Anlık reaktif güç teoremine göre, güç sistemine gönderilen aktif güç $\mathrm{P}=$ Udid ve reaktif güç $\mathrm{Q}=$ Uqiq şeklinde elde edilebilir. $\mathrm{Bu}$ şekilde id ve iq bileşenlerinin kontrol edilmesiyle güç şebekesine aktif ve reaktif güç gönderen sistemin dinamik kontrolünün gerçekleştirilebilme imkanı sağlanmış olur.

\section{Çok Seviyeli Eviriciler}

Günümüz modern teknolojide güç elektroniği çok önemli bir yere sahiptir ve 1s1 denetimi, 1şık denetimi, motor denetimi, güç kaynakları, araç tahrik sistemleri ve FACTS gibi çok geniş kullanım alanlarına sahiptir. Güç elektroniğgi dönüştürme düzenlemelerinden biri olan DC-AC çeviriciler, eviriciler olarak da bilinir. Bir eviricinin fonksiyonu, denetimli genlik ve frekansta bir AC gerilim ya da akım üretmektir. Tipik bir üç-fazlı evirici şeması Şekil 3’te görülmektedir. 


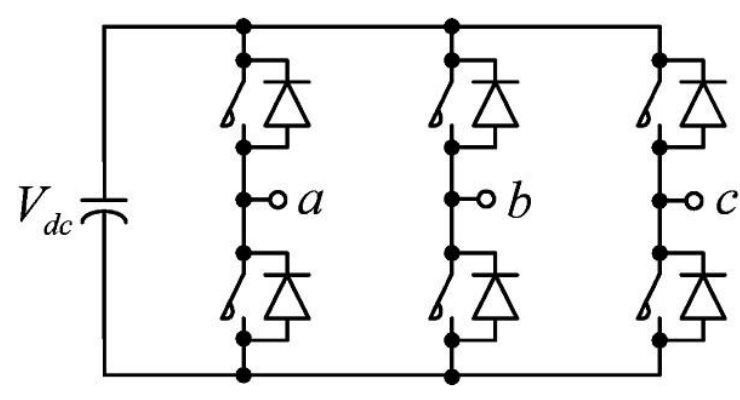

Şekil 3. Üç-fazlı evirici.

Çok seviyeli eviriciler birçok güç yariiletkenlerinden ve kondansatör gerilim kaynaklarından oluşur. Çok seviyeli eviricilerin çıkış gerilimi anahtarlamalardan dolayı kondansatör gerilimlerinin toplamlarını içerir. Şekil 4 çok seviyeli eviricilerin bir faz bacağının diyagramını gösterir. Şekil 4 (a)'da görülen iki seviyeli evirici, kondansatörün negatif bacağından iki seviyeli bir çıkış gerilimi üretir. Şekil 4 (b)'de görülen üç seviyeli evirici ise üç gerilim seviyesi üretir. Böylece düşük gerilimlerdeki güç yariletkenleri ile yüksek gerilimlere ulaşılabilir.

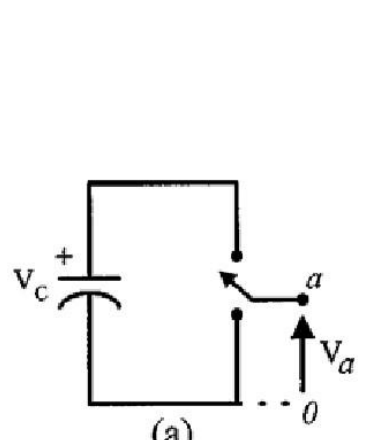

(a)

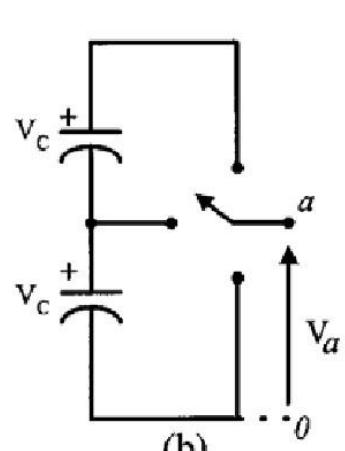

(b)

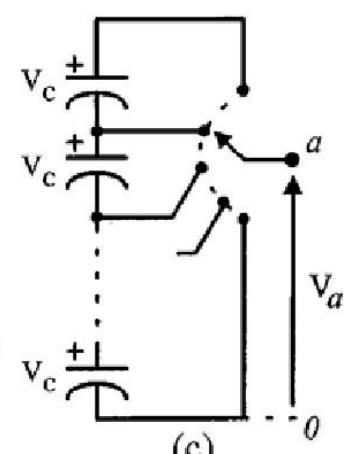

(c)
(a) İki seviyeli
(b) üç seviyeli
(c) n seviyeli

Şekil 4. Bir eviricinin bir faz bacağı.

Çok seviyeli eviricilerin birçok çeşidi bulunmaktadır. Bunlar; diyot kenetlemeli çok seviyeli eviriciler (Nabae ve ark., 1981), kondansatör kenetlemeli çok seviyeli eviriciler (Lai ve Peng, 1996), kaskad çok seviyeli eviriciler (Cengelci ve ark., 1999), hibrit çok seviyeli eviriciler (Lee ve ark., 2002), genelleştirilmiş çok seviyeli eviriciler (Peng, 2001), karışık seviyeli çok seviyeli eviriciler (Hill ve Harbourt, 1999), yumuşak anahtarlamalı çok seviyeli eviriciler (Song ve ark., 2001) vb. şeklindedir. 
Çok seviyeli evirici ailesi yüksek güç uygulamalarına çözüm getirmek amacıyla ortaya çıkmıştır. Bunun yanında, elektrikli araç tahrik sistemleri, aktif güç filtreleri, gerilim çökmeleri için kompanzatörler, fotovoltaik sistemler ve dağıtım güç sistemleri gibi orta ve düşük güç uygulamalarında da düşük maliyet ve etkin çözümler nedenleriyle çok seviyeli evirici uygulamalarının kullanımları yaygınlaşmıştır. Bu çok seviyeli eviricilerin en çok kullanılanları diyot kenetlemeli, kondansatör kenetlemeli ve kaskad çok seviyeli eviricilerdir.

Şekil 5'te bir faz için 3 seviyeli ve 5 seviyeli kaskad H-köprü çok seviyeli evirici yapıları görülmektedir. Kaskad çok seviyeli eviricilerin bazı avantajları vardır. Aynı gerilim seviye sayısını başarmak için diğer tüm çok seviyeli eviricilere göre en az eleman sayısı kullanılmaktadır. Modüler devre modeli ve paketlemesi mümkündür çünkü her seviye aynı elemanlara sahiptir ve ekstradan kenetleme diyotlarına veya gerilim dengeleme kondansatörlerine ihtiyaç yoktur. Bu yapıda kocaman ve kayıplı direnç-kondansatör-diyot söndürücülerinden kaçınmak için yumuşak anahtarlama kullanılabilir. Dezavantaj olarak da aktif güç alışverişi için ayrı DC kaynağa ihtiyaç vardır ve böylece uygulamaları biraz daha limitlidir.
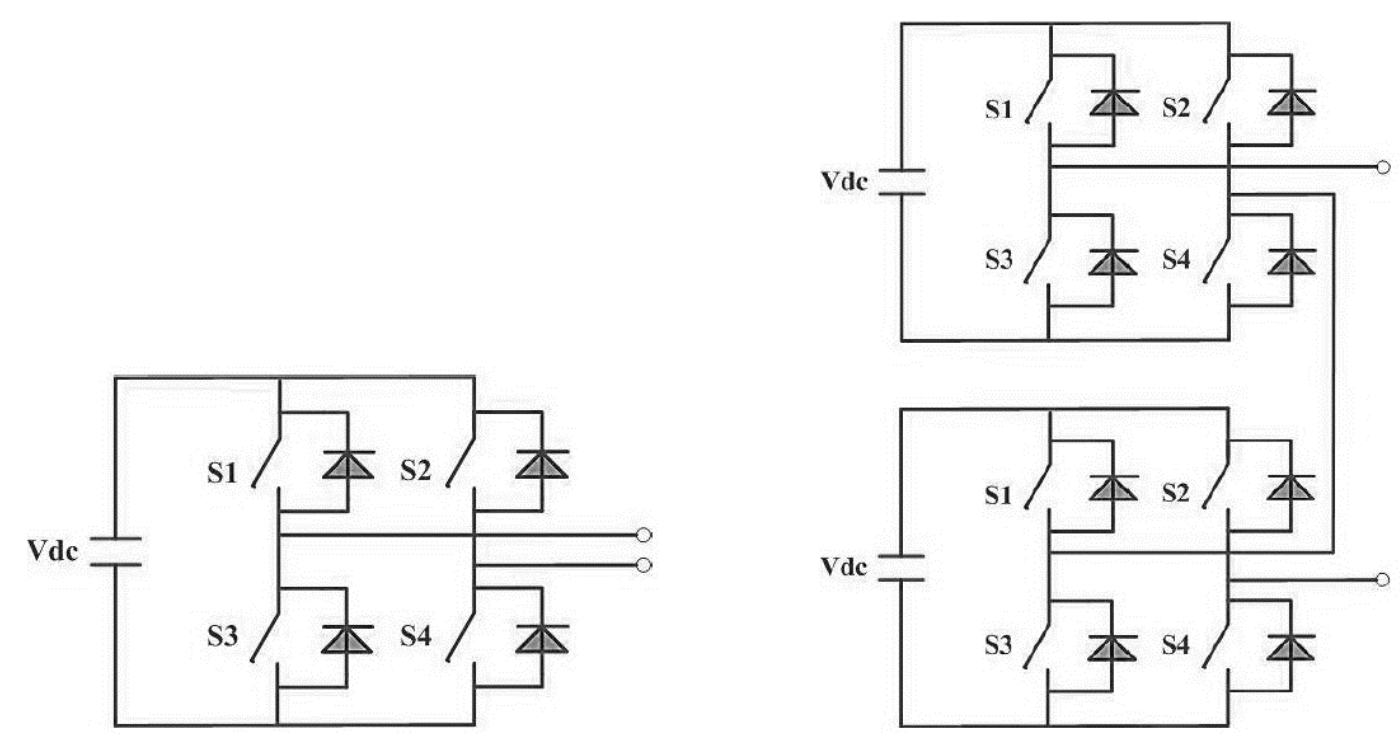

Şekil 5. Kaskad H-köprü çok seviyeli evirici.

Bu tip eviricilerin temel yapısı H-köprü (H-Bridge, HB) bağlantısına dayanır. Şekil 6'da her faz için 2 adet olmak üzere H-köprülü çok seviyeli bir eviricinin güç devresi görülmektedir. Her H-köprü ayrı bir DC kaynak tarafından beslenir. Faz 
gerilimi ise farklı H-köprüler tarafından üretilen gerilimlerin toplamıyla oluşturulur. Eğer H-köprülerin DC link gerilimleri aynı ise çok seviyeli eviriciye kaskad çok seviyeli evirici denir. H-köprü DC link gerilimlerinin birbirlerinden farklı olması durumunda ise hibrit çok seviyeli evirici olarak bilinir.

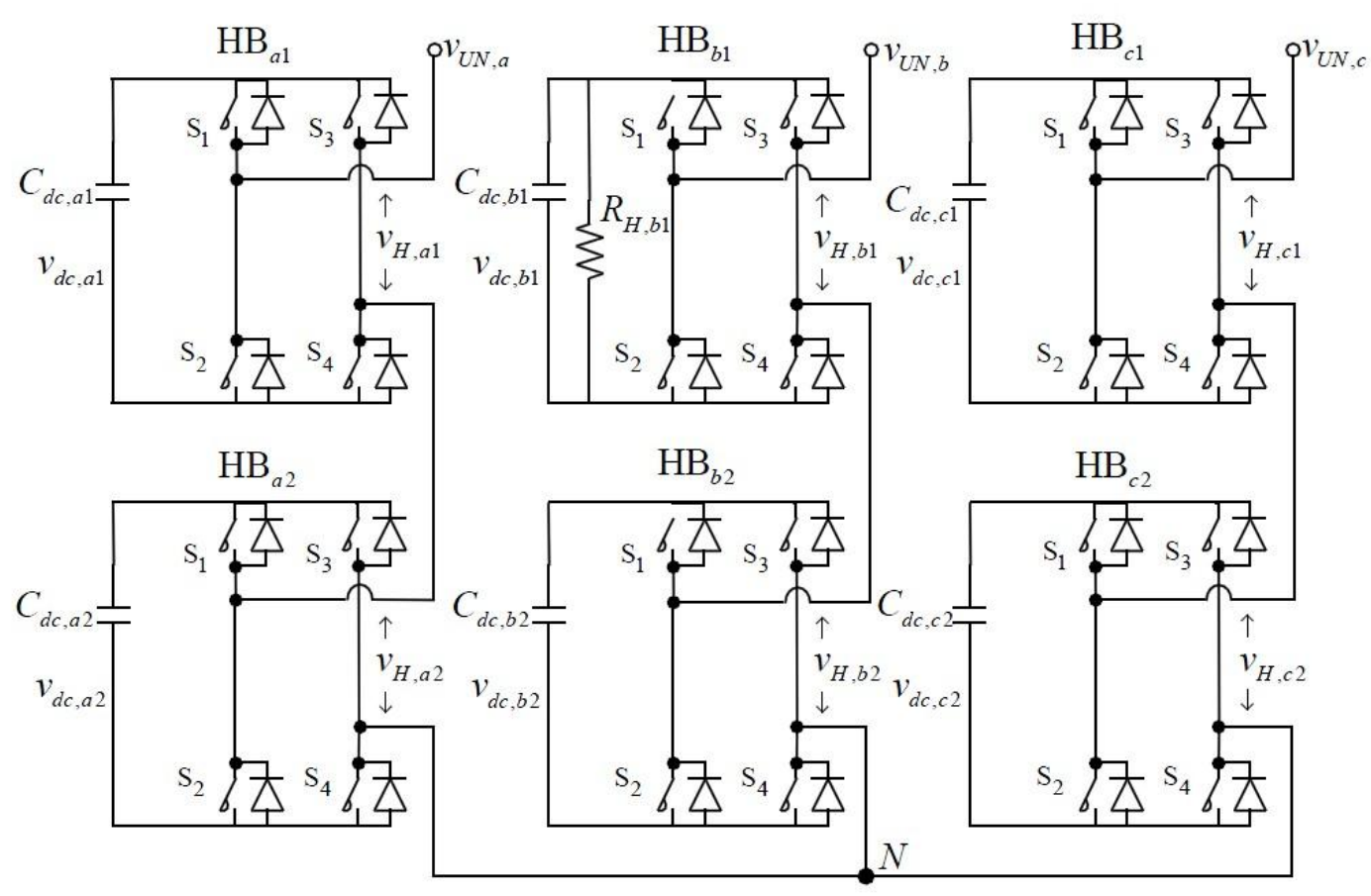

Şekil 6. Beş seviyeli kaskad çok seviyeli evirici yapısı.

Şekil 6'da görülen beş seviyeli kaskad çok seviyeli evirici yapısından hareketle kaskad çok seviyeli eviricilerde H- köprü DC link gerilimleri aynı ise,

$\mathrm{Vdc}, \mathrm{a} 1=\mathrm{Vdc}, \mathrm{a} 2=\mathrm{E}$

olur. Burada E birim gerilimdir. Her H-köprü çıkışında üç gerilim üretilir: $+E, 0$ ve $-\mathrm{E}$. Bu kondansatörlerin ardarda güç anahtarları vasıtasıyla $\mathrm{AC}$ tarafa bağlanmasıyla mümkündür. Çıkış AC gerilimi Şekil 7'de görüldüğü gibi $-2 \mathrm{E}$ ile $+2 \mathrm{E}$ arasında beş seviye olarak değişir. 


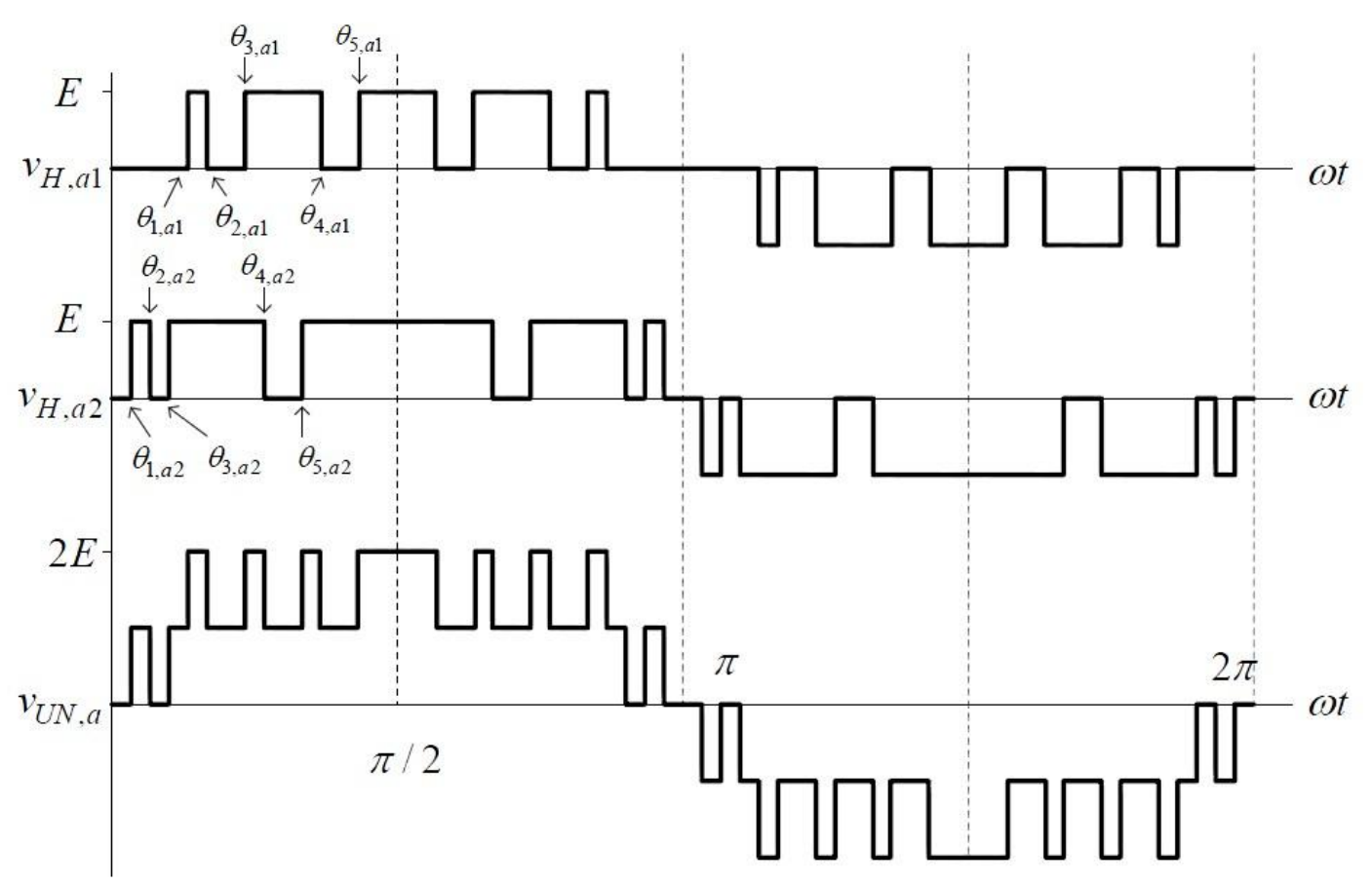

Şekil 7. Beş seviyeli evirici için dalga şekli.

\section{Denetim Yöntemleri}

STATCOM denetiminin ana fonksiyonu, istenilen çıkış gerilimi ile ilgili olarak eviricide her anahtarın açık kapalı peryotlarını hesaplamakla bir takım koordineli zamanlamalı dalga şekli üreterek kompanzasyon için gerekli olan reaktif güç alışverişi yaparak senkron bir çıkış dalga şekli üretmek için evirici güç anahtarlarını anahtarlamaktır.

Çıkış geriliminin genliği ve açısı evirici ile ilgili reaktif akımı hesaplar ve böylece AC sistem ile reaktif güç alışverişi yapılır. İki tane tipik STATCOM denetim şekli vardır. Bunlardan birincisi olan direk denetim metodunda DC gerilimi sabit tutmak ve gerilim denetim mekanizması vasıtasıyla evirici çıkış geriliminin denetlenmesiyle reaktif çıkış akımını direk olarak denetlemek amaçlanmaktadır. İkinci olarak ise dolaylı denetim metodunda $\mathrm{AC}$ çıkış geriliminin genliğinin direk olarak DC kondansatör gerilimi ile orantılı olmasından dolayı DC kondansatördeki ihtiyaç olan DC gerilimi oluşturarak evirici çıkış gerilimi için gerekli genliği ve açıyı sağlar. Bu orantıdan dolayı, DC kondansatör geriliminin denetlenmesiyle (çıkış geriliminin açısını denetleyerek) reaktif çıkış akımı dolaylı olarak denetlenebilir. 
STATCOM'un reaktif gücünün denetimi için doğrudan akım denetim yöntemi, faz açı denetim yöntemi, sabit DC hat gerilim yöntemi, dolaylı akım denetim yöntemi gibi farklı denetim yöntemleri önerilmiştir.

$\mathrm{Bu}$ çalışma için bu yöntemlerden dolaylı akım denetim yöntemi kullanılmıştır. Önerilen bu yöntemlerden Şekil 8'de görülen dolaylı akım denetim yönteminde DC gerilim sabit tutulur ve eviricinin üretmesi gereken referans gerilimler referans aktif ve reaktif güce göre elde edilir.

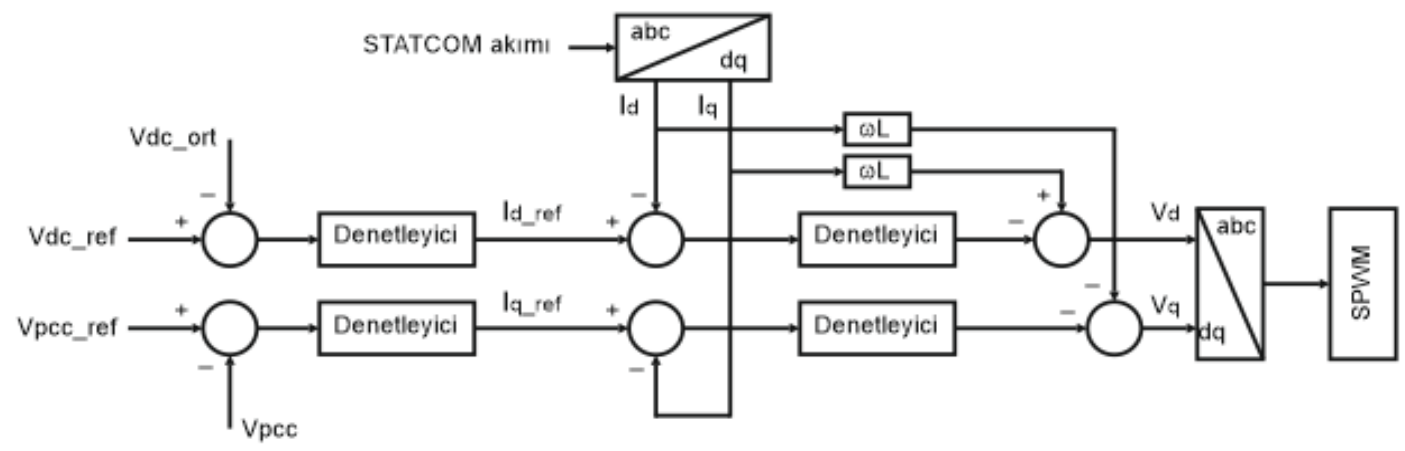

Şekil 8. d-p referans yapı teorili dolaylı akım denetim yöntemi.

\section{Bulanık Mantık Denetleyici}

Bulanık mantığın insan düşünce ve davranışlarını modelleme özelliğinden faydalanılarak birçok alana uygulanması artık olağan hale gelmiş bulunmaktadır. Belirsizlik içeren verilerin temsili ve bulanık karar vermedeki esnekliği nedeniyle kontrol sistemlerindeki kullanımı da sürekli artmaktadır. Güç sistemlerindeki yük değimi ve osilasyonların oluşumundaki belirsizlik ve oluşum sürelerinin rastgeleliği, bulanık mantık tabanlı denetleyicilerin bu alanda kullanımını zorunlu hale getirmektedir. Yük-frekans kontrolü yapılarak oluşan frekans ve güç osilasyonları hızlı bir şekilde söndürülmeye çalışılmaktadır. Burada kullanılan BMD’nin genel akış diyagramı Şekil 9'da görülmektedir. 


\section{Bulanık Mantık Denetleyici}

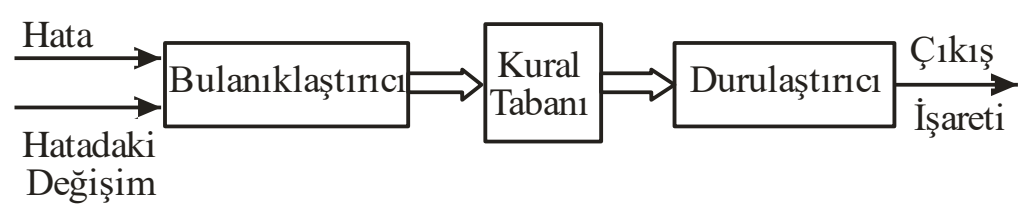

Şekil 9. BMD’nin temel yapısı.

Şekil 9'da görüldüğü gibi sistem 3 parçadan oluşmaktadır. Bunlar sırasıyla, Bulanıklaştırıcı, Kural Tabanı ve Durulaştırıcı'dır. BMD’nin ilk elemanı olan Bulanıklaştırıcı kendisine uygulanan kesin girişleri bulanık değerlere çevirir. Bu bulanık değerler Kural Tabanı ünitesine gönderilerek burada bulanık kurallarla işlenir ve elde edilen bulanık sonuç Durulaştırma ünitesine gönderilir. Bu kısımda ise bulanık sonuçlar kesin sayıya dönüştürülür.

Genellikle BMD’nin giriş değişkenleri kontrol hatası (e) ve bu hatanın bir örnekleme süresindeki değişimi (de) şeklindedir. Bu değişkenlere göre BMD’nin kural tabanı ünitesinde bir kural tablosu oluşturulur. Bu tablo için bir örnek Tablo 1'de gösterilmiştir. Bu tablonun oluşturulmasına yönelik geniş açıklamalar (Altaş ve Sharaf, 2007) de bulunabilir.

Tablo 1. Kural Tablosu.

\begin{tabular}{|c|c|c|c|c|c|}
\hline de & NB & NK & S & PK & PB \\
\hline NB & NB & NB & NK & NK & S \\
\hline NK & NB & NK & NK & S & PK \\
\hline S & NK & NK & S & PK & PK \\
\hline PK & NK & S & PK & PK & PB \\
\hline PB & S & PK & PK & PB & PB \\
\hline
\end{tabular}

Bulanık Mantık Denetleyicide temel elemanlar üyelik fonksiyonlarıdır. Bu üyelik fonksiyonları üçgen, yamuk, sinüsoid, gaussian, çan ve sigmoid tiplerinde olabilir. Yapılan çalışmada üçgen üyelik fonksiyonu kullanılmıştır (Altaş ve Sharaf, 2007).

BMD’nin bulanıklaştırma işleminde giriş uzayından gelen üyelik değerlerinin minimumları alınarak her kural için gerekli ağırlık katsayıları belirlenir. 
Gerekli ağırlık katsayıları bulanıklaştırma ünitesinde belirlendikten sonra bu değerler çarpılmak üzere kuralların işlendiği kısma gönderilir.

Durulaştırma ünitesinde alanların merkezi yöntemi kullanılarak kesin değerler elde edilir. Bu kesin değerler denetleyicinin çıkışıdır.

Daha sonra hız hatası ve bu hatadaki değişimden yola çıkılarak denetleme işlemi yapılmaktadır. Referans hız girişi bulanık üyelik fonksiyonlarının tanımlandığı kesin uzayın alt ve üst sınırlarını belirlemek üzere BMD bloğu içerisinde kullanılmaktadır. Bunun dışında hız hatası ve hatadaki değişim BMD’nin temelde iki kesin girişleridir. BMD’nin çıkışı ise kontrol işaretindeki değişimi vermektedir. Bu değişim bir önceki örneklemede kullanılan denetim işaretine eklenerek yeni denetim işareti elde edilmektedir. Yapılan bu son işlemle BMD’nin etkisi bir integral alıcının etkisine benzetilmiştir.

\section{Sonuçlar ve Tartışma}

$\mathrm{Bu}$ çalışmada iki seviyeli ve beş seviyeli evirici yapılarına sahip STATCOM cihazlarının benzetim çalışmaları yapılmış ve karşılaştırmaları yapılmıştır. Sistemde yük olarak $1 \mathrm{~kW}$ 'lık sabit direnç yükü ile $4 \mathrm{~kW}$ 'lık sabit asenkron motor yüklerine ek olarak 0,3 . saniyede devreye girmek üzere bir adet $3 \mathrm{~kW}$ 'lık direnç yükü ve 0,4 . saniyede devreye girmek üzere $1 \mathrm{~kW}$ 'lik direnç yükü ile $5 \mathrm{kVAr}$ 'lik endüktif yük devreye alınmaktadır. Bu yük değişimleri sırasında STATCOM'lu sistemin performansı incelenmiştir. STATCOM'un kontrolü için senkron referans yapı teorisine dayalı dolaylı akım denetim yöntemi kullanılmıştır. Bu denetim yöntemindeki d ve q eksen akımlarının kontrolünde Bulanık Mantık Denetleyici (BMD) kullanılmaktadır. Sistemin ana yapısının Matlab/Simulink modeli Şekil 10'da görülmektedir. 


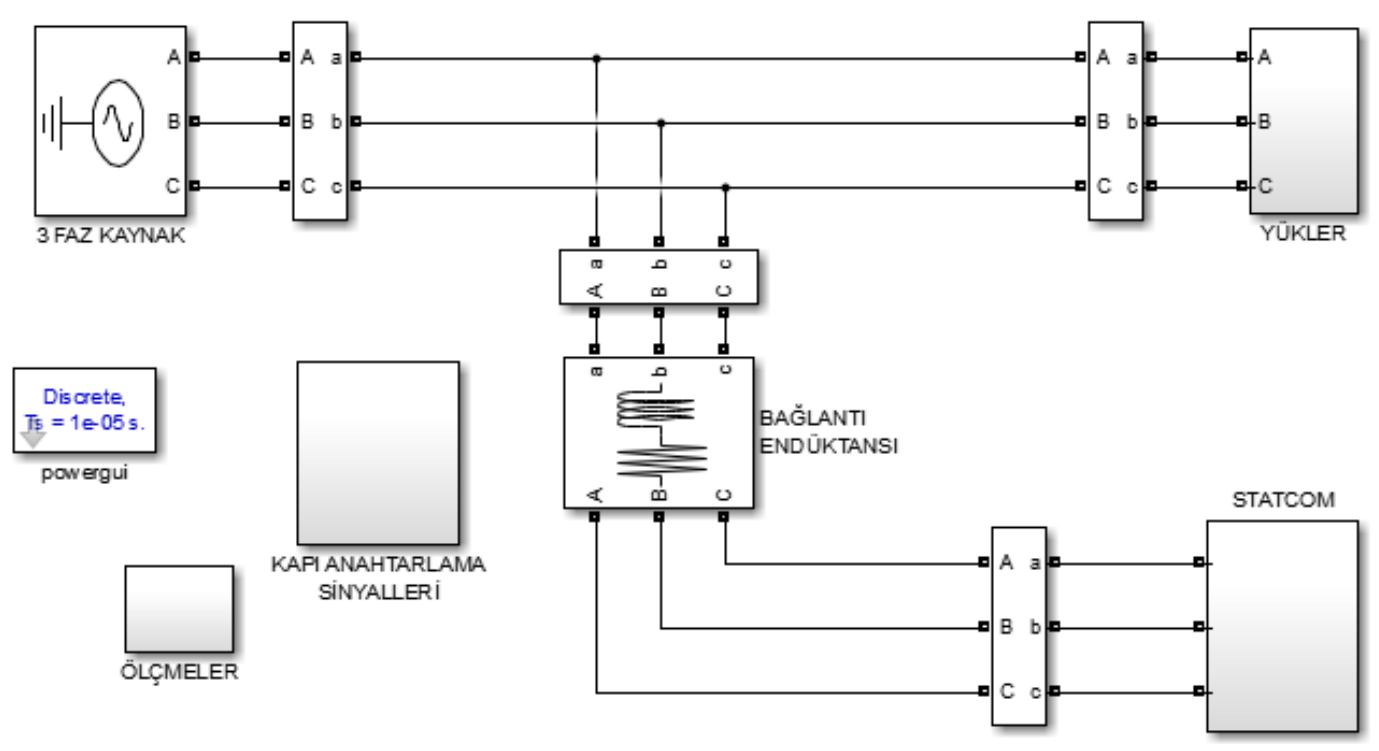

Şekil 10. Sistemin ana yapısının Matlab/Simulink modeli.

Şekil 11 ve Şekil 12 incelendiğinde güç kalitesi açısından STATCOM hem iki seviyeli hem de beş seviyeli bağlantıda faz farkını istenildiği gibi ortadan kaldırmaktadır.

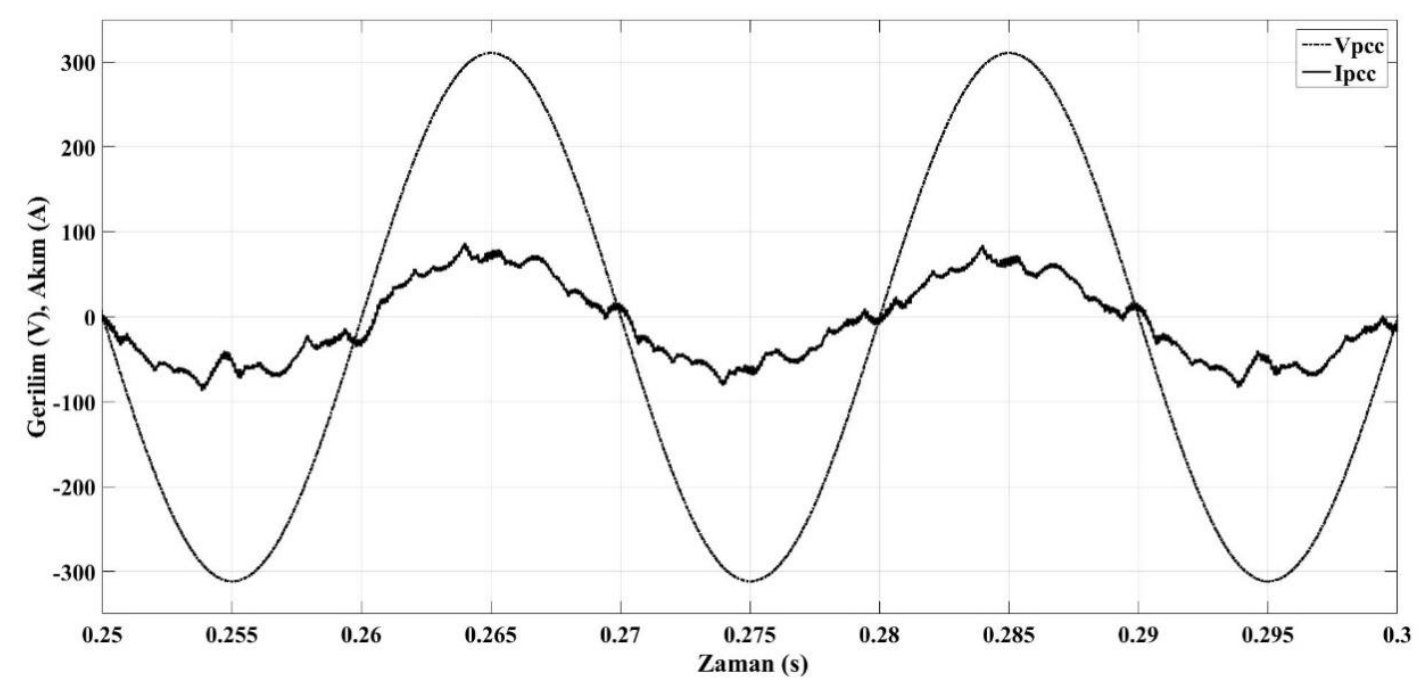

Şekil 11. Ortak bağlantı noktasındaki akım gerilim değişimleri (İki seviyeli STATCOM). 


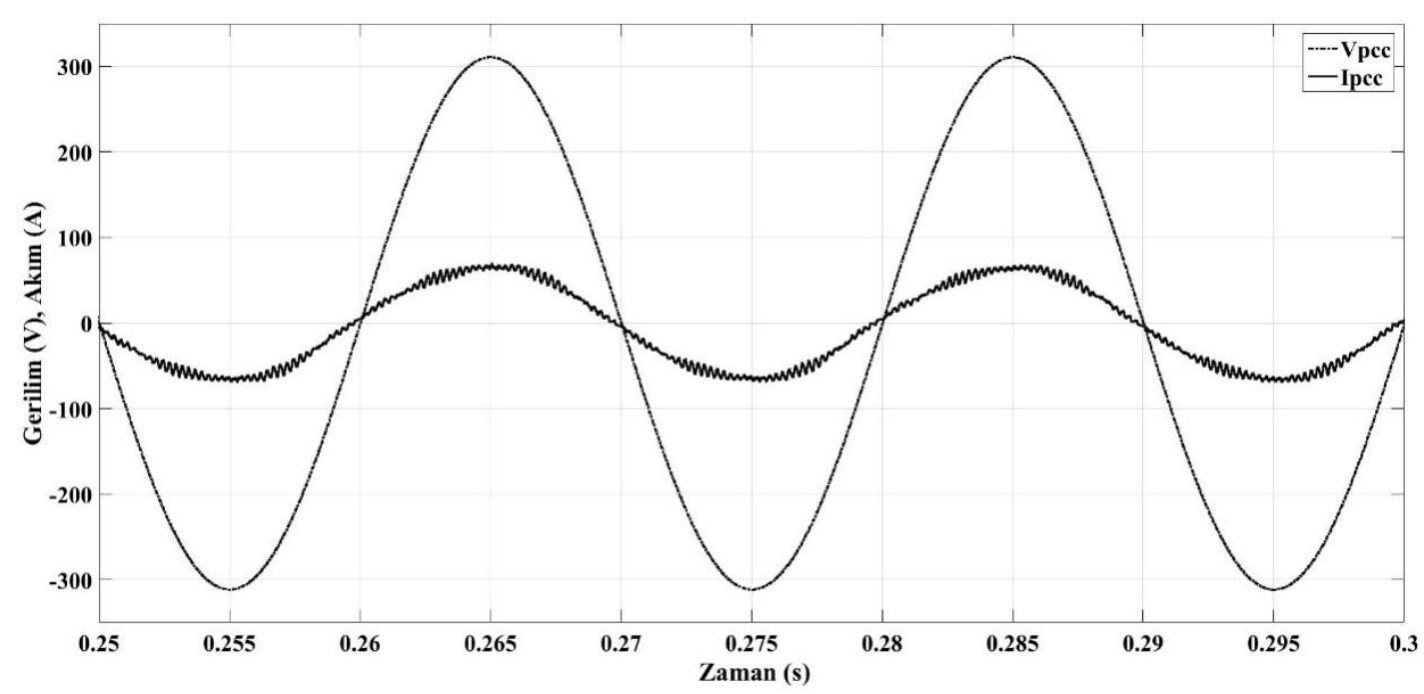

Şekil 12. Ortak bağlantı noktasındaki gerilim ve akım (x10) değişimleri (Beş seviyeli STATCOM).

Şekil 13'de ve Şekil 14'te sırasıyla iki seviyeli ve beş seviyeli STATCOM'un evirici çıkışındaki faz-faz gerilimleri görülmektedir.
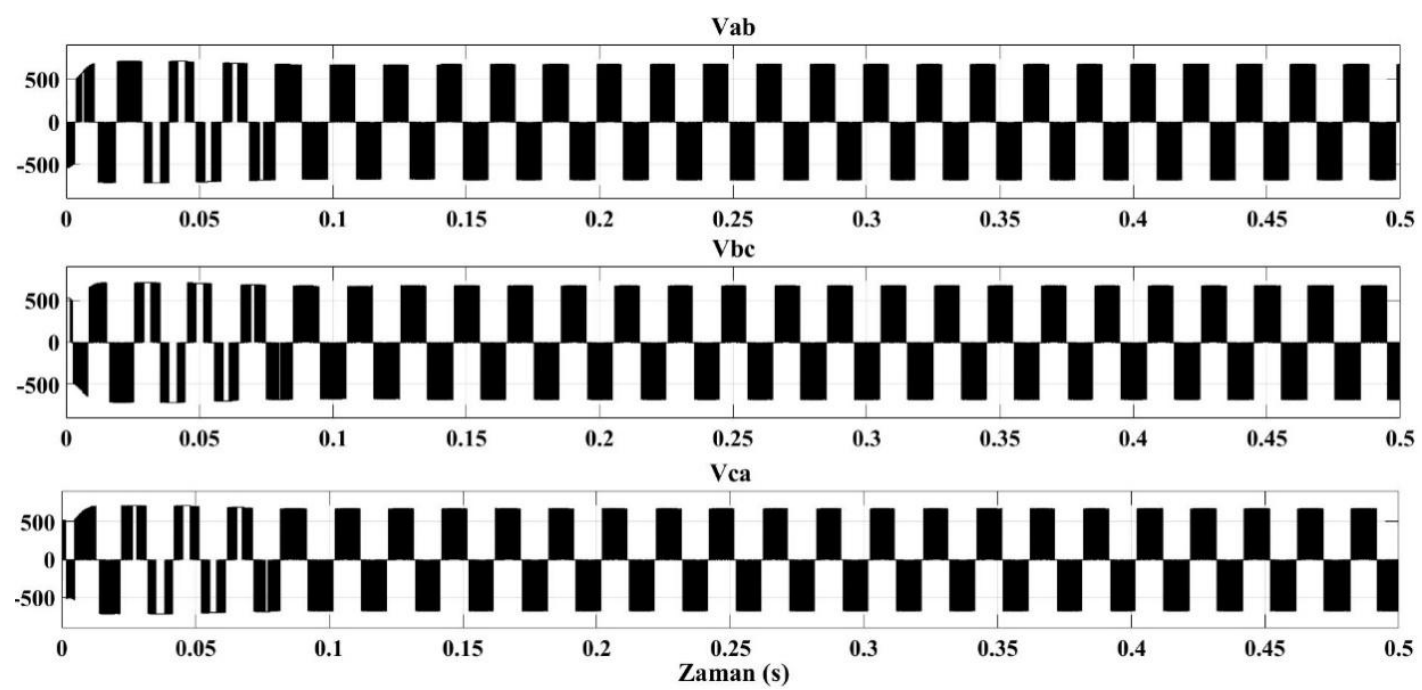

Şekil 13. İki seviyeli STATCOM’un evirici çıkışındaki faz-faz gerilimleri. 


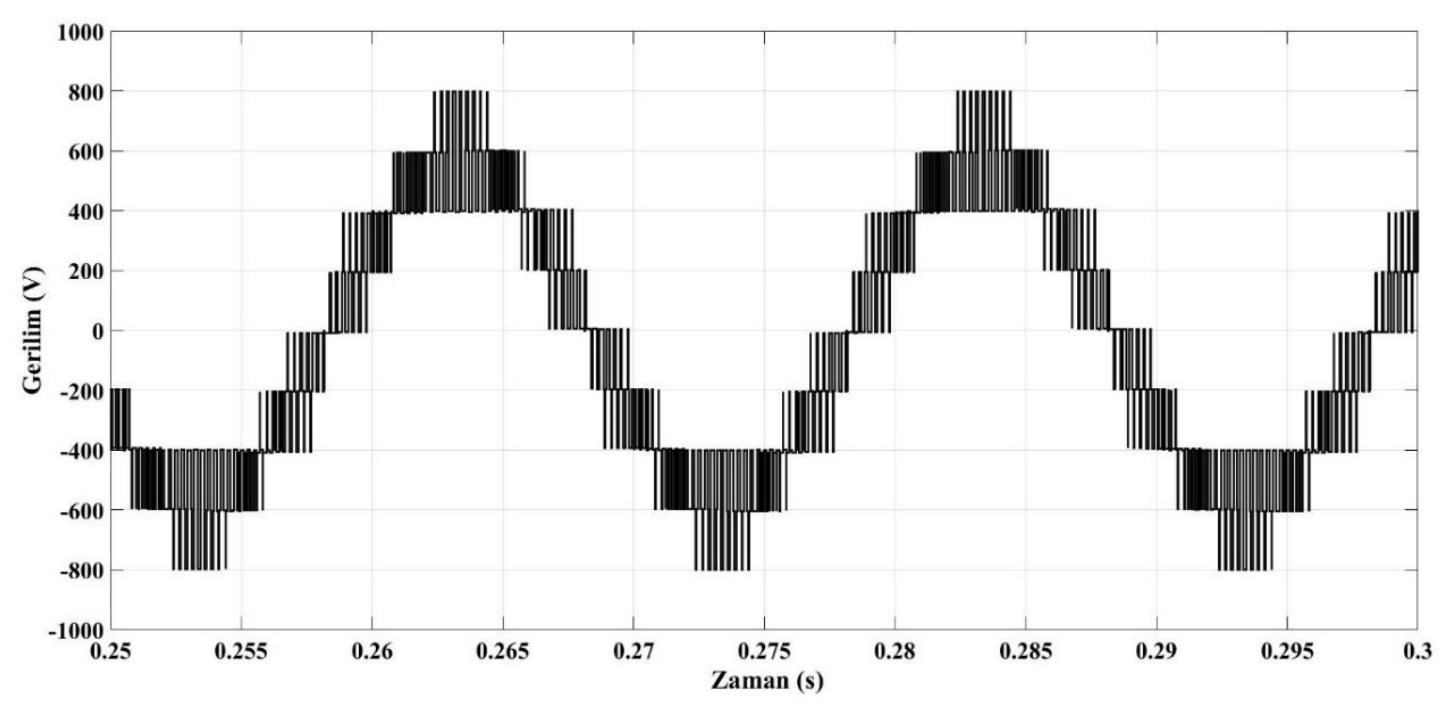

Şekil 14. Beş seviyeli STATCOM'un evirici çıkışındaki faz-faz gerilimi.

Şekil 15'te ise beş seviyeli STATCOM'un bir fazında bulunan iki adet H-köprü çıkış gerilimleri ve bunların toplamı alt alta görülmektedir. Burada H-köprülerin toplamı olan Va gerilimi dalga şeklinde beş seviye net bir şekilde görülmektedir.

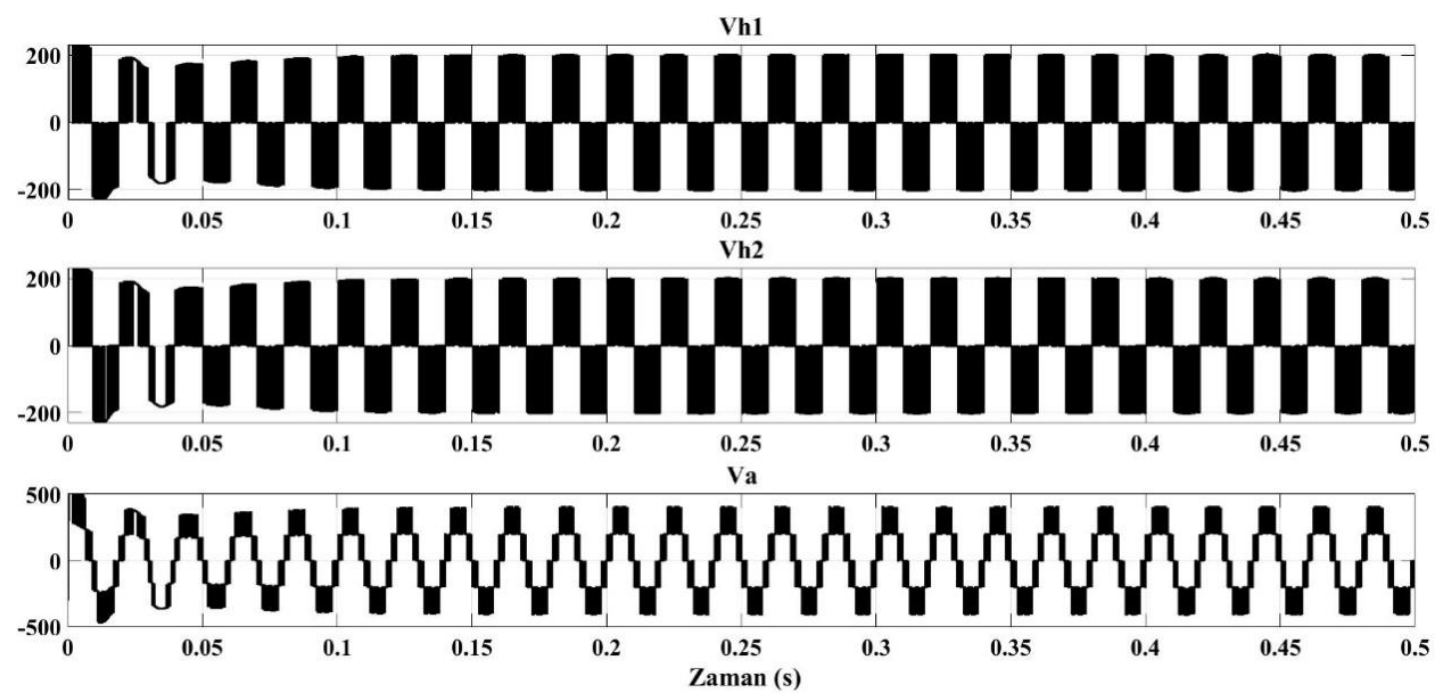

Şekil 15. Beş seviyeli STATCOM'un evirici çıkışındaki bir faz gerilimi.

Şekil 16'te iki seviyeli STATCOM'lu sistem ile beș seviyeli STATCOM'lu sistemin reaktif güçlerinin karşılaştırması yapılmıştır. 


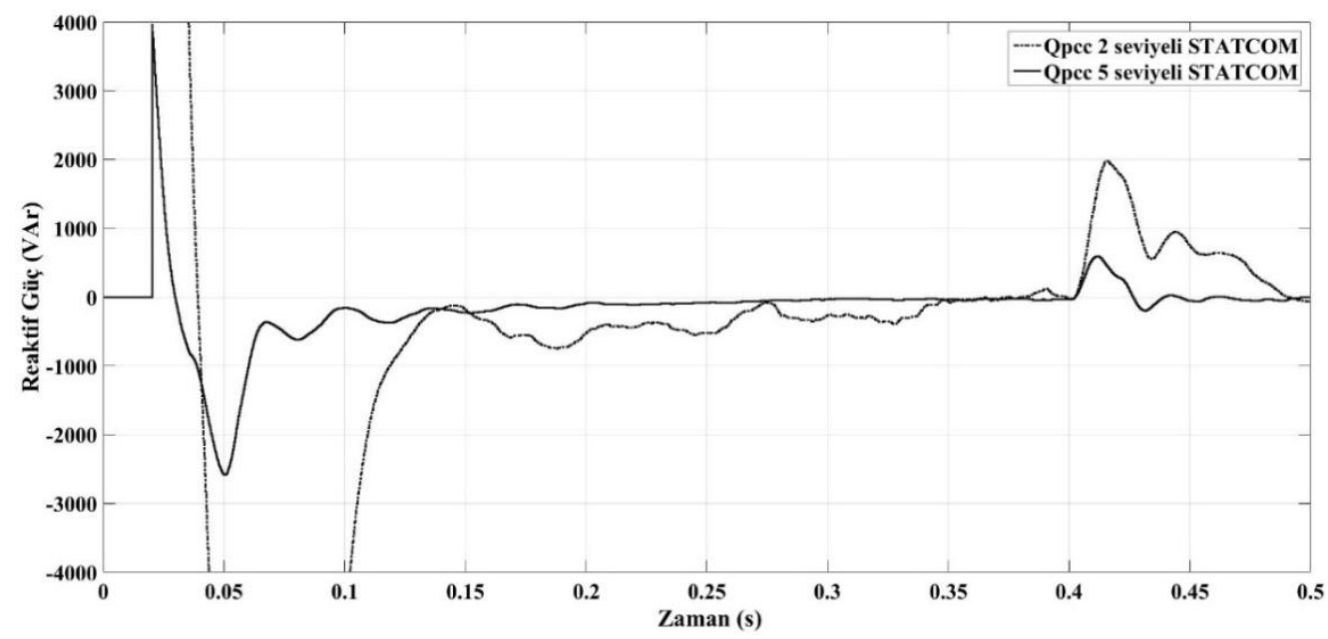

Şekil 16. İki seviyeli ve 5 seviyeli STATCOM reaktif güç karşılaştırmaları.

Şekil 16' da sisteme beş seviyeli STATCOM bağlı iken reaktif güç istenildiği gibi sıfır seviyesinde başarılı bir şekilde kalmaktadır. Sonuç olarak beş seviyeli H-köprü temelli gerilim kaynaklı eviricili STATCOM cihazı iki seviyeli olanına göre her açıdan çok daha hızlı ve çok daha iyi sonuçlar vermektedir.

\section{Teşekkür}

Bu çalışma, TÜBİTAK-114E474 No.lu "Küçük Ölçekli Rüzgar Türbinlerinde Yeni Ve Akıllı Bir STATCOM Tasarımı Ve Uygulaması” isimli proje kapsamında yürütülmüştür. Yazarlar, sağlanan destekten dolayı TÜBİTAK’a teşekkür ederler.

\section{Kaynaklar}

Abdallah, M., Faltas, S.N. 1998. Reproductive Biology of Trigla lucerna and Trigloporus lastoviza in the Egyptian Mediterranean Waters. Bull. Nat. Inst. of Ocean. \& Fish., A.R.E., (24): 285-304.

Baron, J. 1985a. Les Triglides (Teleosteens, Scorpaeniformes) De La Baie De Douarnenez. 1-La croissance de Eutrigla gurnardus, Trigla lucerna, Trigloporus lastoviza et Aspitrigla cuculus. Cybium, 9 (2): 127-144.

Campillo, A. 1992. Les pêcheries françaises de Méditeranée: synthèse des connaissances. Institut Francais de Recherche pour Exploitation de la Mer, France.

Dorel, D. 1986. Poissons de Atlantique nord-est relations taille-poids. Institut Francais de Recherche pour Exploitation de la Mer. Nantes, France.

Mediterranean coast of Turkey. Turk. J. Fish. Aquat. Sci, 7:37-40.

Altaş, I. H. ve Sharaf, A. M., 2007. A Generalized Direct Approach for Designing Fuzzy Logic Controllers in Matlab/Simulink GUI Environment. International Journal of Information Technology and Intelligent Computing, Int. J. IT\&IC, (4), 1.

Cengelci, E., Sulistijo, S., U., Woo, B., O., Enjeti, P., Teoderescu, R. ve Blaabjerg, F. 1999. A new medium-voltage PWM inverter topology for adjustable-speed drives. IEEE Transactions on Industry Applications, (35),3: 628-637. 
Çetin, A. ve Ermiş, M., 2009. VSC-Based D-STATCOM With Selective Harmonic Elimination. IEEE Transactions on Industry Applications, 45, 3: 1000-1015.

Hill, W., A. ve Harbourt, C., D. 1999. Performance of medium voltage multi-level inverters. Conference Record of the 1999 IEEE Industry Applications Conference Annual Meeting, (2): 1186-1192.

Kazmierkowski, M. P. ve Malesani, L., 1998. Current Control Techniques for Three-Phase VoltageSource PWM Converters: A Survey. . IEEE Transactions on Industrial Electronics, (45),5: 691703.

Lai, J. S. ve Peng, F., Z., 1996. Multilevel converters-a new breed of power converters. IEEE Transactions on Industry Applications, (32),3: 509-517.

Lee, C., K., Ron Hui, S., Y. ve Chung, H., S.-H., 2002. A 31-level cascade inverter for power applications. IEEE Transactions on Industrial Electronics, (49),3: 613-617.

Nabae, A., Takahashi, I. and Akagi, H., 1981. A new neutral-point clamped PWM inverter. IEEE Transactions on Industry Applications, IA-17, 5: 518-523.

Peng, F., Z., 2001. A generalized multilevel inverter topology with self voltage balancing. IEEE Transactions on Industry Applications, (37), 2: 611-618.

Song, B.-M., Kim, J., Lai, J.-S., Seong, K.-C., Kim, H.-J. ve Park, S.-S., 2001. A multilevel softswitching inverter with inductor coupling. IEEE Transactions on Industry Applications, (37),2: 628-636. 